\title{
Study on Design of Elastic Support for Wind Turbine
}

\author{
Xingmei Lv, Xiangyan Ruan, Jie Zhong, Xiuzhen Li \\ (CRRC ZHUZHOU INSTITUTE CO.,LTD., WIND POWER UNIT ZhuZhou,HuNan,412001,China)
}

\begin{abstract}
In this paper, the $2 \mathrm{MW}$ generator system is taken as an example. Firstly, the modal frequency of the system is obtained by theoretical calculation, FEA analysis and experimental test. The comparison of the three methods shows that the system frequency is calculated by using the mass point and rigid beam simplified generator model. It has a certain reliability, and greatly simplifies the selection of the elastic support of the wind turbine. Secondly, the DOE method is used to analyze the sensitivity of the wind turbine's elastic support stiffness by the integration of ABAQUS and Isight software. Finally, the stiffness is optimized by algorithm. This is the first time that the method of designing the elastic support for wind turbine is deeply studied, which provides a scientific reference for the reasonable selection.
\end{abstract}

\section{INTRODUCTION}

The elastic support of the generator for wind turbine is a flexible structure connecting the generator and the rear frame, and its function is mainly to reduce the vibration transmitted from the generator to the rear frame. As the installed capacity of wind power continues to increase and the operating time of wind turbine increases, problems related to vibration have become more prominent [1]. Therefore, the selection of elastic support as key components of the vibration reduction system is particularly important. In the process of selecting the elastic support, the stability of the wind turbine will be better if its stiffness is large enough, but its vibration damping performance will be greatly reduced, which will affect the entire drive-train system and the rear frame. Disadvantageously, the stability of the generator will become poor if its stiffness is too small,especially in the emergency shutdown conditions or yaw process of the wind turbine, the generator will appear greater shaking, so the stiffness of the elastic support choose a reasonable value to avoid resonance, which will affect the stability of the wind turbine [2]. At present, excessive horizontal vibration of the generator has appeared during the operation of wind turbine, which has caused the fracture of the elastic support and threaten the safety of the wind turbine. Therefore, it is particularly urgent and important to do in-depth research on the selection and design of elastic support.

This article will focus on the selection and design methods of the elastic support. On the one hand, it is difficult for the generator suppliers to provide detailed generator geometric models for the OEM to select the elastic support. Therefore, this article uses three methods to calculate the frequency of the generator system. Three analytical models are solved and determined according to the results.A simplified model is used to simulate the rationality of the generator. On the other hand, by analyzing the sensitivity of the stiffness to the system frequency, it provides a scientific reference basis for the OEM to select the elastic support of the generator.

\section{MODAL CALCULATION OF GENERATOR SYSTEM}

This chapter uses three different calculation methods to calculate the frequency of horizontal vibration for the generator system. The parameters of the generator used are shown in Table 1.

Table.1 The Main Parameters of Generator

\begin{tabular}{|r|r|}
\hline parameters & value \\
\hline length $(\mathrm{m})$ & 1.6 \\
\hline width $(\mathrm{m})$ & 1.1 \\
\hline $\begin{array}{c}\text { Ixx }\left(\mathrm{kg} \cdot \mathrm{m}^{2}\right) \\
\text { moment of inertia }\end{array}$ & 2400 \\
\hline $\begin{array}{c}\text { Iyy }\left(\mathrm{kg} \cdot \mathrm{m}^{2}\right) \\
\text { moment of inertia }\end{array}$ & 4920 \\
\hline $\begin{array}{c}\left.\text { Izz (kg.m }{ }^{2}\right) \\
\text { moment of inertia }\end{array}$ & 4200 \\
\hline weight $(\mathrm{kg})$ & 8830 \\
\hline
\end{tabular}

\subsection{ENGINEERING CALCULATION MODAL FREQUENCY}

When selecting the elastic support of the generator, the $\mathrm{X}$ (axial), Y (lateral), and Z(vertical) stiffness are mainly considered to match the rationality of the system. Without considering the flexibility of the rear frame, the 
horizontal vibration frequency of the generator system is calculated as follows [3-5]:

Torsional vibration around the $\mathrm{Z}$ axis:

$$
\omega_{\varphi \mathrm{z}}^{2}=\left(\mathrm{k}_{\mathrm{y}} \sum \mathrm{a}_{\mathrm{i}}^{2}+\mathrm{k}_{\mathrm{x}} \sum \mathrm{b}_{\mathrm{i}}^{2}\right) / \mathrm{I}_{\mathrm{z}}
$$

(1) $\quad \mathrm{K}_{\mathrm{x}}$ and $\mathrm{K}_{\mathrm{y}}$ represent the stiffness of elastic support in the $\mathrm{X}$ and $\mathrm{Y}$ directions respectively. $\mathrm{a}_{\mathrm{i}}$ is the distance between the elastic support and the center of gravity of the generator in the $\mathrm{X}$ direction, $\mathrm{b}_{\mathrm{i}}$ is the distance between the elastic support and the center of gravity of the generator in the $\mathrm{Y}$ direction, $\mathrm{Iz}$ are the moments of inertia of the generator around the $\mathrm{Z}$ axis.

According to formulas 1, the torsional frequency around $\mathrm{Z}$ axis is $26.19 \mathrm{~Hz}$ which causes the current excessive vibration of the generator in the wind farm.

\subsection{FINITE ELEMENT METHOD TO CALCULATE MODAL FREQUECNY}

The generator system mainly includes three components which are generator, elastic support and rear frame. The generator is a complex system, including stators, rotors, bearings, coolers and other structures. In the wind power industry, many generator suppliers have a certain degree of confidentiality for their structures, so it is difficult for OEM to obtain the three-dimensional model of the generator, the mass points and rigid beams are used to simulate the generator in the finite element analysis of the generator system. In order to simulate the boundary of the generator system more accurately, the rear frame is included in FE model. Figure 1 shows FE model of the generator system.

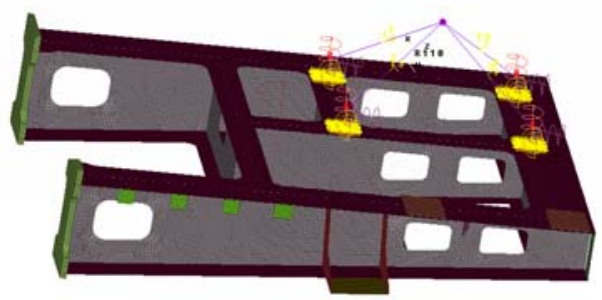

Fig.1 FE Model of Simple Generator System

The elastic support of the wind turbine is simulated by spring elements, and its stiffness is shown in Table 2 .

Table.2 The Stiffness of Elastic Support

\begin{tabular}{|c|c|}
\hline Transverse Stiffness & $30000 \mathrm{~N} / \mathrm{mm}$ \\
\hline Transverse Stiffness & $10000 \mathrm{~N} / \mathrm{mm}$ \\
\hline Axial Stiffness & $30000 \mathrm{~N} / \mathrm{mm}$ \\
\hline
\end{tabular}

The frequency of torsional mode around $\mathrm{Z}$ axis by FEA is $23.905 \mathrm{~Hz}$.Figure 2 shows the modal shape and frequency when the generator vibrates.

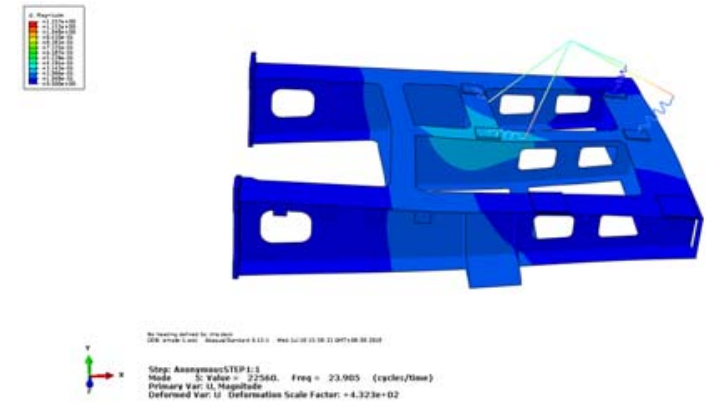

Fig.2 Torsional Mode Around Z Axis

\subsection{MEASUREMENT RESULTS OF WIND FARM}

In the wind farm, the natural frequency of the system is tested by two methods which are the knocking method and the installation of horizontal acceleration sensors on the generator drive end, as shown in Figure 3.

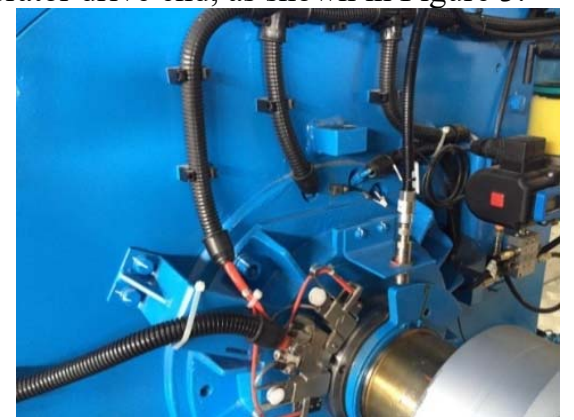

Fig.3 The Acceleration Sensor Is Installed At The Drive End Of Generator

\subsubsection{KNOCKING TEST}

It is found that the natural frequency around $\mathrm{Z}$ axis is $23.35 \mathrm{~Hz}$ by the method of knocking, and the natural frequency is analyzed repeatedly $(\geq 3)$. The measured frequencies are shown in Table 3.

Table.3 Natural frequency of tapping test

\begin{tabular}{|c|c|}
\hline \multicolumn{2}{|c|}{ Knocking measurement (Upwind direction) } \\
\hline Detection location & Natural frequency \\
\hline $\begin{array}{c}\text { Front left } \\
\text { (Low speed shaft side) }\end{array}$ & 23.36 \\
\hline Back left & 23.27 \\
\hline $\begin{array}{c}\text { Right front } \\
\text { (Coupling side) }\end{array}$ & 23.42 \\
\hline Right back & 23.37 \\
\hline
\end{tabular}

\subsubsection{REAL-TIME TEST OF WIND TURBINE OPERATION (SCADA DATA)}

During the operation of the wind turbine, in order to monitor the operation status of the wind turbine, the wind turbine is equipped with a SCADA system. This system refers to the installation of acceleration sensors on the important structure of the drive-train system. The drive end and the non-drive end are equipped with acceleration sensors. Fig. 4 shows the acceleration signal 
measured at the drive end of the generator through integration in order to obtain the trend of the effective value of speed with the generator speed.There is a sudden change at 1250 1520rpm $(20.8 \sim 25.3 \mathrm{~Hz})$. The main reason is that the natural frequency of the generator system is close to the rotation frequency, and resonance has occurred. By converting the time domain spectrum to the frequency domain spectrum, as shown in Figure 5, it can be seen that the generator has a $1 \mathrm{P}$ resonance at the speed of 1400 (the frequency of rotation is $23.27 \mathrm{~Hz}$ ).

Through the knocking method and the test of the generator vibration during the operation of the wind turbine, the natural frequency of the generator system is $23.3 \mathrm{~Hz}$.

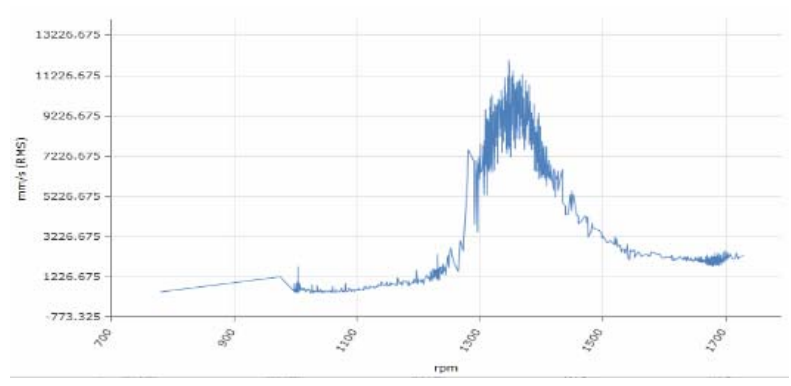

Fig. 4 The Trend Of The Effective Speed Of Generator Vibration With Rotational Speed

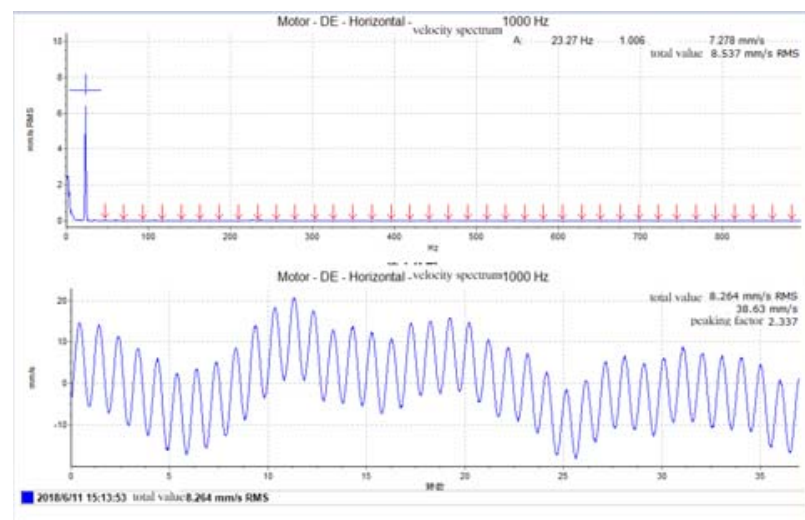

Fig. 5 Vibration Velocity Spectrum Of 1400r/min During Generator Idling

The frequency of the torsion around the $\mathrm{Z}$ axis are very different by three methods. According to the results, the flexibility of the rear frame should be fully considered when selecting the elastic support. What's more, it can be seen that mass points and beam elements can be used for simulation. Under the premise of ensuring the accuracy of analysis, the difficulty of establishing analysis models is reduced, and the selection efficiency of elastic support is improved.

\section{GENERATOR SYSTEM TEST DESIGN}

According to the above analysis, within the rotational frequency range of the generator, the frequency of the torsion around the $\mathrm{Z}$ axis is close to the system frequency, so the resonance is prone to occur. In order to avoid this phenomenon, it is necessary to re-select the elastic support of the wind turbine.

\subsection{DESIGN OF EXPERIMENTS}

Design of Experiments (DOE) is suitable for product development and process optimization. Its goal is to maximize or optimize the key characteristics of product. Through experimental design, the influence of key factors and the interaction between factors can be identified.

The structure of the elastic support of the wind turbine is shown in Figure 6. The elastic support in this article is circular, and its lateral stiffness and axial stiffness are the same.

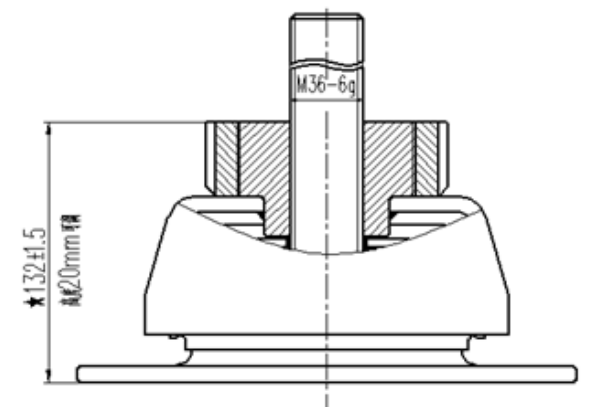

Fig.6 The Structure Of Generator Elastic Support

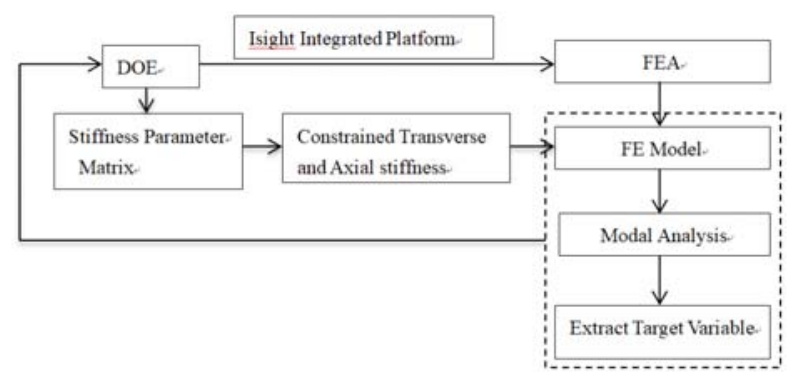

Fig.7 Design Flow Of DOE

In order to study the sensitivity of elastic support stiffness to the system frequency, the parametric optimization software Isight is integrated with the finite element analysis software Abaqus, and the optimal Latin hypercube design algorithm [9] (Opt LHD) is used. The advantage is that all designed test points are distributed as evenly as possible in the design space in order to have a good space filling and balance. The DOE design process is shown in Figure 7 and Figure 8.

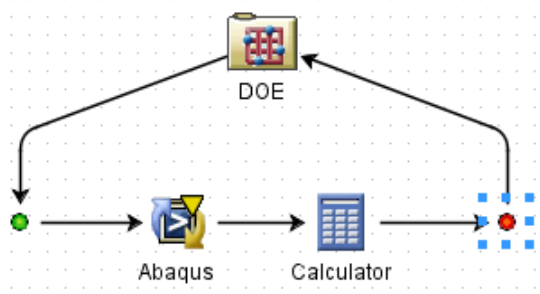

Fig.8 Isight And Abaqus Integration Process 


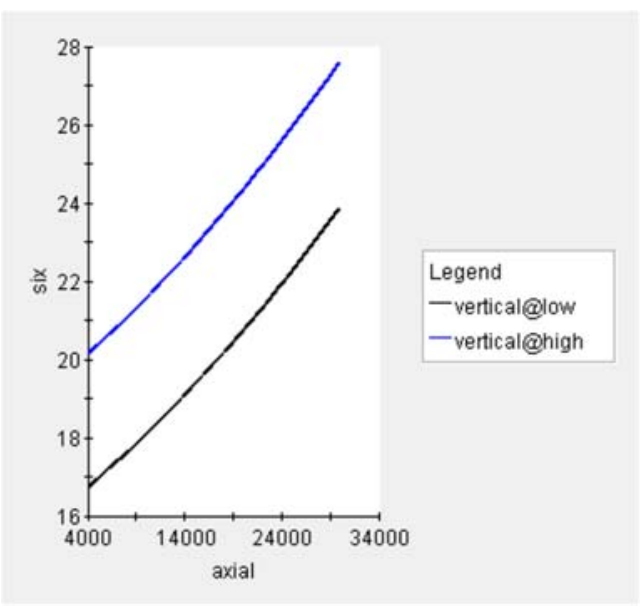

Fig. 9 Interaction Diagram Between Axial

And Vertical Stiffness And System Natural Frequency

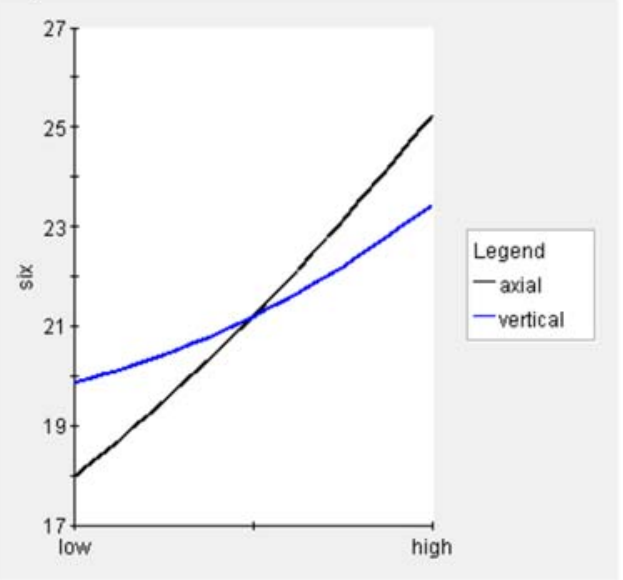

Fig.10 Main Influence Diagram Of Axial And Vertical Stiffness On System Natural Frequency

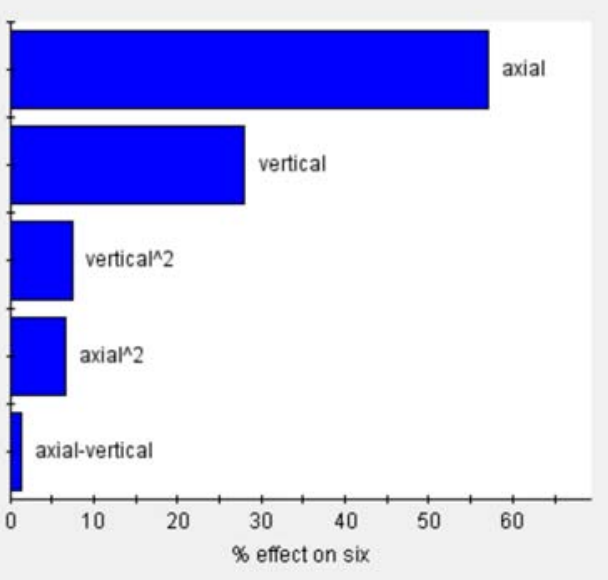

Fig.11 Pareto Diagram Of Axial And Vertical Stiffness On System Natural Frequency

According to Figure 9-11, it can be seen that the axial stiffness and vertical stiffness have no interaction on the rotating frequency of the generator.As the axial and vertical stiffness go from low to high, the system frequency within the rotating frequency increases almost linearly. Both the axial and vertical stiffness have a positive effect on the rotation frequency, the axial stiffness has a greater effect. therefore, the axial stiffness is easier to change the natural frequency of the system than the vertical stiffness.

\subsection{OPTIMAL DESIGN}

\subsubsection{OPTIMIZATION MODEL ESTABLISHMENT}

In this paper, a simplified generator FE model is used, At the Isight integrated platform, the three-dimensional stiffness $\mathrm{Kx}, \mathrm{Ky}$, and $\mathrm{Kz}$ of the elastic support are used as optimized design variables. According to the structural characteristics of the elastic support, Kx equals Ky . Due to the decline of stiffness, the strength and carrying capacity of the elastic support will decrease. Based on the experience, the stiffness of the elastic support of the wind turbine generator should be greater than $4000 \mathrm{~N} / \mathrm{mm}$. Therefore, the constraints of the design variables are $4000 \leq \mathrm{Kx} \leq 30000$ and $4000 \leq \mathrm{Kz} \leq 30000$.

the vibration isolation performance of the elastic support can be judged by the frequency ratio[10-12].

$$
\mathrm{z}=\frac{\mathrm{f}_{\mathrm{m}}}{\mathrm{f}_{\mathrm{n}}}
$$

$f_{m}$ is the excitation frequency; $f_{n}$ is the natural frequency.

When $\mathrm{z}$ is between 0.8 and 1.2 , the system is in the resonance zone; the system is in the transition zone when $z$ between 1.2 and $\sqrt{2}$; the system is in the isolation zone when $\mathrm{z}$ is more than $\sqrt{ }$ 2.In this paper, we use the second continuous programming optimization algorithm (NLPQL) to optimize the design.

\subsubsection{OPTIMIZE DESIGN RESULTS}

The optimization results are shown in Table 4. When determining the lateral stiffness, the relationship between the vibration damping performance of the elastic support and its strength needs balance.

Table.4 The Results Of Optimal Design

\begin{tabular}{|c|c|c|c|}
\hline & Unit & $\begin{array}{c}\text { Orginal } \\
\text { Project }\end{array}$ & $\begin{array}{c}\text { Optimal } \\
\text { Project }\end{array}$ \\
\hline axial stiffness & $\mathrm{N} / \mathrm{mm}$ & 30000 & 4500 \\
\hline transverse stiffness & $\mathrm{N} / \mathrm{mm}$ & 30000 & 4500 \\
\hline vertical stiffness & $\mathrm{N} / \mathrm{mm}$ & 10000 & 4000 \\
\hline $\begin{array}{c}\text { 4th Modal } \\
\text { frequency }\end{array}$ & $\mathrm{Hz}$ & 17.279 & 9.96 \\
\hline $\begin{array}{l}\text { 5th Modal } \\
\text { frequency }\end{array}$ & $\mathrm{Hz}$ & 23.905 & 10.94 \\
\hline $\begin{array}{l}\text { 6th Modal } \\
\text { frequency }\end{array}$ & $\mathrm{Hz}$ & 24.653 & 11.7 \\
\hline $\begin{array}{l}\text { 7th Modal } \\
\text { frequency }\end{array}$ & $\mathrm{Hz}$ & 34.048 & 30.69 \\
\hline
\end{tabular}

It can be seen that although the natural frequency of the optimized scheme system coincides with the lowest rotational frequency of the generator, the vibration energy of the generator is very small when the speed of generator is the lowest, what's more, the running time is short. During the operation of the wind turbine, the 
generator is basically running at the rated speed, so the system can avoid resonance caused by the unbalanced force of the generator. In addition, the ratios of the sixth and seventh order frequencies to the generator's rated frequency of $20 \mathrm{~Hz}$ are 1.7 and 1.53 respectively, their values are both greater than $\sqrt{2}$, so the elastic support has a good vibration isolation effect.

\section{RESULT}

1) In the modal analysis of the generator system, a simplified generator model can be used (only considering the mass and moment of inertia of the generator), which greatly reduces the modeling difficulty and time period;

2) When selecting the elastic support stiffness of the wind turbine, the flexibility of the rear frame should be fully considered;

3) In order to avoid resonance, the natural frequency of the system should be avoided from the rotation frequency of the generator as far as possible. Therefore, under the premise of certain strength, the elastic support has better vibration isolation performance with smaller rigidity.

\section{References}

1. Kusiak A,Zhang Zijun.Analysis of Wind Turbine Vibrations based on SCADA data[J].Journal of Solar Energy Engineering, 2010,132(3):1-12

2. Yan hongwen,Tian Hongqi,Lv Xingmei,et al. Research on Vibration Analysis and Control of a Large Wind Turbine[J]. Acta Energiae Solaris Sinica, 2016, 37(6):1617 1622

3. Mechanical vibration manual[M]. Mechanical Industry Press:QuWeide,(1992)

4. Cheng rong.Research on Technology used in Vibration Isolation System of Wind Turbines.Jiangsu:Jiangsu University of Science and Technology,2014:39-41

5. Zhu Jianshi,Lou Jingjun,He Qiwei,et al.Vibration Theory and Vibration Isolation[M].Beijing:National Defense Industry Press (2008)

6. Chen Kewei.Dynamic Characteristics and Experimental Investigation of Power Unit Vibration Isolation Systems[D].Ji nan:Shangdong University(2013)

7. Shi Yi.Research on Technology of Vibration Measurement in Wind Turbine[D].Urumqi:Xin jiang Agricultural University(2007)

8. WangYongsheng,Zhao Ping,Yang liu et al.Research on Vibration Isolation Characteristics of Flexible Mounting for MW Grade Wind Turbine Gearbox[J]. Acta Energiae Solaris Sinica,2016,37(10): 2688 2694

9. Lai Yuyang, Jiang Xin, Fang Liqiao, et al. Isight parameterization optimization theory and examples [M]. Beijing: Beijing University of Aeronautics and Astronautics Press, 2012,88-122.
10. Peng Tiandong.Dynamic Characteristics of Motor Vibration Reduction Technology Research Based on the Vibration Damping Pad[D].Hu nan:Hunan University of Science and Technology(2014)

11. Wen Bin,Li Shuqiang,Tong Shiwei et al. Vibration of wind power doubly fed generator based on ADAMS[J].Machinery,2017,55(629):71-74

12. Wen Bin, Tong Shiwei, Cheng Linzhi et al. Vibration Fault Analysis of Wind Turbine Doubly-Fed Generator[J].Electromechanical Engineering,2014,31(8):1071 1076 